Accepted refereed manuscript of: Briguglio M, Delaney L \& Wood AM (2018) Partisanship, priming and participation in public-good schemes. European Journal of Political Economy, 55, pp. 136-150. DOI: 10.1016/j.ejpoleco.2017.11.007

(C) 2017, Elsevier. Licensed under the Creative Commons Attribution-NonCommercial-NoDerivatives 4.0 International http://creativecommons.org/licenses/by-nc-nd/4.0/

\title{
PARTISANSHIP, PRIMING AND PARTICIPATION IN PUBLIC-GOOD SCHEMES
}

\section{Authors: Marie Briguglio Liam Delaney $_{\mathrm{b}}$ Alex Wood $_{\mathrm{c}}$}

a. Department of Economics, Faculty of Economics Management and Accountancy, University of Malta, Tal-Qroqq, MSD2080 and Behavioural Science Centre, Stirling Management School, University of Stirling, Stirling FK9 4LA, United Kingdom (marie.briguglio@um.edu.mt)

b. Behavioural Science Centre, Stirling Management School, University of Stirling, Stirling FK9 4LA, United Kingdom and University College Dublin, Geary Institute (liam.delaney@ucd.ie)

c. Behavioural Science Centre, Stirling Management School, University of Stirling, Stirling FK9 4LA, United Kingdom (alex.wood@stir.ac.uk)

Corresponding Author: Marie Briguglio + 3567909 9909, marie.briguglio@um.edu.mt Department of Economics, Faculty of Economics Management and Accountancy, University of Malta, Tal-Qroqq, Msida MSD2080, Malta.

\begin{abstract}
This study tests whether psychological attachment to a political party influences voluntary participation in a government-promoted public-good scheme, positing that cooperation is higher among households that identify with the party in government and lower among households that identify with the party in opposition. The focus is participation in a voluntary recycling scheme, in the context of a European country (Malta) where two parties dominate the political landscape. A nationally-representative survey $(n=1,037)$, yielded information on recycling participation rates and on environmental and political preferences. The survey was conducted shortly after a change in government and also gauged intent to participate in a new scheme with a split-sample manipulation in which the treatment group received a political prime. The results indicate that the initial uptake of the scheme launched by a Nationalist government was significantly lower among respondents close to the Labour Party. Five years later this effect had decayed. But intent to participate in the hypothetical scheme was lower among respondents close to the party in opposition (this time, the Nationalist Party), if primed with a cue that associates the new scheme with the Labour party. Formal modeling of scheme participation and intent (controlling for political and environmental ideology inter alia), yielded consistent results. These findings shed light on a new dimension which may be responsible for diverse rates of uptake of a public good schemes with practical implications for scheme promotion.
\end{abstract}

\section{Keywords}

Politics; partisanship; household; public goods; prime; recycling

\section{Highlights}

- Nationally-representative survey with split-sample priming experiment

- Cues associating a scheme with government create asymmetric outcomes

- Attachment to the party in opposition suppresses cooperation with government

- Results confirmed under two different administrations pre and post-election

- Political preferences co-determine household recycling cooperation 


\section{Introduction}

This study investigates the relationship between partisanship and the willingness of households to voluntarily contribute to public goods. More specifically, it examines whether closely identifying with a political party stimulates contribution to a government-promoted voluntary recycling scheme, if that party is in government, and dampens it, if that party is in opposition. The need to examine how partisanship effects behaviour (beyond voting) has been flagged in recent contributions (Gerber and Huber 2010; Boudreau and MacKenzie 2014; Sunstein 2014), and the question remains underexplored in recycling specifically, and public goods more generally.

Although a handful of studies on pro-environmental behaviour do consider the roles of political vote, ideology or political interest (Torgler and García-Valiñas 2007; Costa and Kahn 2013; Dupont and Bateman 2012; Coffey and Joseph 2013; McBeth, et al 2013; Briguglio, et al 2015, ), there appear to be none which parse out party identification as a distinct determinant of voluntary cooperation. Party identification is a form of psychological attachment to a party, often acquired quite early in life and typically manifesting itself in stable voting preferences, and which may strengthened by the screening out of threatening information (Marsh 2006). It is a type of social identity (Campbell, et al 1960; Lewis-Beck, et al 2008), considered to be more stable and less cognitive than political interest or ideology (Campbell, et al 1960). The term "negative partisans" has been used to describe those who feel strongly against the party in government (Crewe 1976). The premise in this paper is that, aside from their ideological

preferences, individuals may feel sufficiently attached to the party in government to derive 
satisfaction from contributing to public goods promoted by that party, or attached enough to the party in opposition to act in defiance of government's efforts.

The study employs a rich data set drawn from a dedicated nationally-representative telephone survey $(n=1,037)$, carried out in a European context (Malta), where two dominant parties characterise the political landscape, and where a change in government had recently occurred. Data on recycling behaviour and intent, on scheme attributes, and on environmental and political preferences, made it possible to formally investigate the relationship between political attachment and participation, while controlling for other determinants. The survey also gauged intent to participate in a new scheme (under a new government) with a split-sample manipulation, in which the treatment group received a political prime, namely a piece of information which allowed them to infer an association between the scheme with the new government, without providing more detailed knowledge. ${ }^{1}$ Although priming experiments have gained momentum (Lenz 2009; McDermott 2002), applications in the field of recycling are still limited (Croson and Treich 2014).

\section{Literature Review}

\subsection{Household cooperation in public-good schemes}

\footnotetext{
${ }^{1}$ In this study, we refer to this treatment as a prime. We recognize that there are inconsistencies across disciplines in the use of the term "prime" versus "frame", and that these terms are sometimes used interchangeably (See Druckman et al. 2009 for a discussion).
} 
Within the broad literature on household cooperation in public-good schemes, recycling participation has drawn considerable scholarly attention. This not only reflects policy-makers' concern with ever increasing volumes of household waste and its associated environmental impacts (Briguglio 2016; OECD 2008), but also the availability of rich data, capable of offering valuable lessons for other public-good domains (Kinnaman and Takeuchi 2014). Much like behaviour in other public-good domains, recycling requires households to utilise private resources, but its benefits (such as the diversion of waste from landfill and reduction of harmful emissions) are public, enjoyed collectively by all members of society (Briguglio 2016). In scenarios like this, economic models built on the assumption of purely self-interested agents predict little voluntary contribution - such agents would opt to free-ride on the efforts of others (Baumol and Oates 1988). Intervention is therefore considered necessary to tip the cost-benefit trade-off to favour participation (Hahn 1989). In turn, much of the literature has focused on the role of fees to discourage mixed waste disposal (Fullerton, et al 2010) and, increasingly, of convenience to relieve the time and space required to separate waste (Jenkins, et al 2003; Sidique, et al 2010; Lange, et al 2014).

In economic studies on waste, households are often modelled as constrained utilitymaximisers: Their members give up leisure-time and space to separate waste for recycling and weigh the cost of doing so against the benefits derived from participating. Recent work has given greater attention to the role of moral preferences that household members may hold, as drivers of participation. The process of cooperation in public-good schemes allows household members to fulfil moral preferences and generates a private so-called "warm-glow" benefit (Andreoni 1990), or suppresses the guilt of not cooperating (Brekke, et al 2003). A review of empirical studies concludes that such motives may indeed be important determinants 
(Kinnaman 2006), large enough to stimulate voluntary recycling even if this involves private costs (Briguglio, et al 2015; Czajkowski, et al 2014; Abbott, et al 2013; Halvorsen 2008). Insights from environmental psychology further suggest that, underpinning such motives, are important priors like awareness of consequences, belief in the efficacy of action and ascription of responsibility (Schwartz 1977; Biel and Thøgersen 2007). Recycling participation is, in fact, generally found to increase with knowledge or awareness (Jenkins, et al 2003) and educational effort (Sidique, et al 2010), although communication campaigns which fail to contribute to recycling effort are also documented (Valle, et al 2005).

\subsection{The role of political preferences and cues}

In applied work, moral motives are often proxied by some measure of environmental attitude or behaviour (Viscusi, et al 2011; Halvorsen 2008; Abbott, et al 2013; Czajkowski, et al 2014; Brekke, et al 2003; Hage, et al 2009; Bruvoll and Nyborg 2004). Vote or political affiliation data have been used as proxies for environmental motives, but the results are mixed: Recycling is found to be higher among Green Party supporters in Sweden (Hage and Söderholm 2008) and among non-voters (possibly in protest against waste fees) in Norway (Halvorsen 2008). The vote variable has also often found to be an insignificant determinant (Brekke, et al 2010; Coffey and Joseph 2013; McBeth, et al 2013), but Brekke and his colleagues have argued that ignoring its effect could lead to exaggerated predictions of other moral effects (Brekke, et al 2010). The broader environmental economics literature reveals a relationship between political and environmental preferences, namely that ideologically leftwing supporters tend to have stronger pro-environmental preferences (Dupont and Bateman 2012), being willing to pay higher financial contributions to environmental organisations 
(Neumayer 2004), and demonstrating stronger support for environmental taxes (Torgler and García-Valiñas 2007). Higher political interest also correlates with stronger environmental concern (Torgler and García-Valiñas 2007; Wakefield, et al 2006).

Political preferences can be activated by communication cues, yielding diverse cooperative outcomes. In a US-based study, the way recycling benefits were framed interacted with respondent ideology to influence intent to recycle (McBeth, et al 2013). Furthermore Democrats and Liberals recycled more than Conservatives and Republicans, but only if these showed strong interest in political news (Coffey and Joseph 2013). Diverse outcomes were again observed among Liberals and Conservatives, in response to an energy conservation nudge (Costa and Kahn 2013). In the US again, suitable framing of the Affordable Care Act (emphasizing the role of the private sector) narrows the partisan gap in uptake between Republicans and Democrats (Lerman et al 2017). Voting outcomes and promotional effort also significantly explained regional variation in the uptake of a voluntary recycling scheme in Malta (Briguglio, et al 2015).

These findings chime with the literature from economic psychology which suggests that, in a world where decision-makers have limited capacities to assess all aspects, communication can make one dimension more salient than others, and influence decision outcomes, in different ways among different audiences (Glaeser 2014; Thaler and Sunstein 2008; Tversky and Kahneman 1986). Hence, in determining cooperation in public-good schemes, there is scope not only for investigating the role of political preferences per se (Dupont and Bateman 2012), but also of how these interact with communication cues (Costa and Kahn 2013; Schultz, et al 2007; Bolsen, et al 2014; McBeth, et al 2013). Such 
considerations may be particularly relevant at the time of initial rollout of a public-good scheme, for this is when public communication is most intense (Graber and Smith 2005; John 2013) and when political cues are likely to be present. Though these may be ignored by some households, they may be picked up by those with strong political preferences (Graber and Smith 2005). Bolsen et al (2014) identify the kind of factors (such as explicit inducements to form an accurate opinion, and bipartisan support for the law) that can condition such partisanmotivated reasoning (Bolsen, et al 2014).

A question which remains unexplored is whether political attachment is a political preference worthy of examination. A number of theoretical insights converge to suggest so. Firstly, partisanship may shape perceptions about policy and provide a lens through which to assess decisions (Campbell, et al 1960). Whether as tendency to blindly follow the "tribe", or as a reasonable act of taking of cues from a party that shares one's interest (Lenz 2009), those who feel attached to the party promoting a scheme may be more receptive to it, relying on narratives from trusted political sources to simplify complex scientific information (McBeth, et al 2013). By corollary, those who closely identify with the party in opposition may view the intervention (proposed by the government) with prejudice. This type of sentiment (among conservatives, of liberals), has been touted as an obstacle to climate regulation in the United States (Sunstein 2014). Secondly, as party identification is also linked with identification with fellow party supporters (Green, et al 2004), a sense of "togetherness", (Heyman and Ariely 2004; Ahn, et al 2010), may also work in favour of participation when government, led by one's own party, is promoting it. In contrast, the pleasure of spite may motivate those who identify strongly with the party in opposition (Abbink and Sadrieh 2009). Finally, simple selfinterest may be the mechanism that drives both cooperative and non-cooperative behavior 
among partisans, in a bipolar political scenario, for cooperating with government, increases the chances of the incumbent winning the next election, and reduces the odds of the party in opposition. Such factional loyalty can be particularly tense around elections (Boissevain 1993).

\subsection{Synthesis and Hypotheses}

In synthesis then, the literature finds that recycling participation to be driven by warmglow benefits, and these benefits are typically considered to stem from the fulfilment of environmental preferences. But it is also plausible that such benefits (and costs) derive from the fulfilment of political preferences and that such preferences can be activated by political cues. The question which this study asks is precisely whether linking a public-good scheme to the party in government, creates diverse behavioural outcomes, depending on whether households are positively attached to the party in government to the party in opposition, or to no party in particular. To this end, we set out to test three hypothesis.

Hypothesis 1: The uptake of a public-good scheme is positive in attachment to the party in government (for example, uptake of a scheme launched by the Nationalist Party is higher among households attached to the Nationalist party).

Hypothesis 2: The uptake of a public-good scheme is negative in attachment to the party in opposition (for example, uptake of a scheme launched by the Nationalist Party is lower among households attached to the Labour party). 


\section{Hypothesis 3: Support for a scheme becomes more partisan, the stronger the links}

between the scheme and the party in government (for example during scheme promotion and in the presence of cues that link a scheme to the party).

\section{Context and Survey}

\subsection{Context}

The role of political attachment is likely to be more strongly felt in contexts where preferences are polarised, where political parties have a strong presence in governance (Katz 1987), and where competition between parties is not based on (obvious) ideological differences (Marsh 2006). Malta offers the perfect context in this regard: It reports one of the highest voter turnouts in the world, and politics are dominated by two parties with limited ideological distinctions: The centre-left Labour Party called "Partit Laburista" (Labour Party) and the centre-right Nationalist Party called "Partit Nazzjonalista" (Nationalist Party) (IDEA 2004; Lane 2009). Strong, stable party loyalties characterise politics in Malta and one party's gain in votes is the other one's loss (Briguglio 2009; Boissevain 1993). Both parties enjoy strong social networks, their own television and radio stations, newspapers, and clubs all over the country (Baldacchino 2002). In March 2013, general election turnout was 93 per cent and 98 per cent of first-count votes went to one of these two parties (Department of Information 2013). The election resulted in a change of government, from one led by the Nationalist Party to one led by the Labour Party. The survey for this study was launched within two months of this election.

Malta's drive to stimulate household waste recycling followed accession to the EU in 2004 (European Environment Agency 2013). In May 2008, two months after the general 
elections had reconfirmed the Nationalist Party in Government, the responsible Ministry had introduced, and promoted, a door-to-door recycling-waste collection scheme. The scheme would offer collection of dry recycling waste, at least once a week, in special grey bags. These could be purchased for a small fee, though some were provided for free. Households could also discard recycling waste in unmanned waste receptors in each locality. Mixed municipal waste collection continued to be offered door-to-door, almost daily, without quantity restrictions and free of charge. Despite the lack of incentive and the nuisance of separating and storing recycling waste, uptake was positive (Briguglio, et al 2015). It continued to increase when the scheme was delegated from the Ministry to Local Councils, and later to private operators (National Statistics Office Malta 2013).

Figure 1 summarises the time line of events that contextualise the six month period during which data was gathered for this study. The survey, described next, sought to measure initial uptake of the scheme launched by the Nationalist government (as at 2008), participation rates at the time of the survey (2013) as well as intent to participate in a hypothetical new scheme to be launched by the Labour government.

\section{Figure 1 Time-line of events}

\subsection{Sample generation}

Data for the study was drawn from a nationally-representative survey conducted by a team of trained enumerators. Computer Assisted Telephone Surveys were used to avoid biasing responses towards literate respondents and avid recyclers, a problem that is typical of self- 
administered surveys (Hage, et al 2009). A face-to-face mechanism would have limited sample size, given budgetary constraints. The sampling frame was generated from the Maltese electoral register.

To ensure that households had an equal probability of being captured (no matter their size) household members were aggregated, then randomly sampled, with up to four replacements, from natural next-row choice (to cater for drop-outs). Telephone numbers were matched using on-line directories. Interviews were then conducted with the household member answering the telephone, provided they confirmed that they were aged 18 years or over. A total of 1,037 responses were generated in this way. Figure 2 indicates that the regional distribution of these households was highly representative of that of the whole population of Maltese households (which totals 142,310). A comparison of the sampled household characteristics with those of national data (National Statistics Office 2012a) also indicates very similar characteristics (described in 3.5 below). Telephone respondents were, however, more likely to be female, which explains why the sample is female-skewed relative to the Maltese population.

\section{Figure 2 Distribution of households by region in sample, population}

\subsection{Survey instrument}

The interview itself was developed after an extensive review of recycling studies and following interviews with waste separation operators and regulators to identify the actual scheme attributes. Pan-European surveys (including the European Social Survey and Eurobarometer) were reviewed for comparable questions on politics and the Maltese Census 
was used as a reference for wording on demographic questions. Following clearance by the Ethics Committee at the University of Stirling, a pen-and-paper pilot study was conducted in October $2012(n=100)$. The syntax was kept very simple, any unfamiliar terms were defined and scales were kept similar between questions, with ranges specifying exact frequencies (Tourangeau, et al 2000). The interview was professionally translated into the Maltese language and programmed into Qualtrics software to allow use of randomisation options and to reduce inputting error.

The first set of questions yielded data on household characteristics and constraints, including household size, composition, dwelling type and locality. The second set of questions required respondents to describe the recycling scheme in operation in their locality (collection frequency, price, types of waste, information sources) as perceived by households (Valle, et al 2005). In the third section, respondents were asked if their household separated waste for doorto-door collection in recent weeks, usingthe wording: "In the past 4 weeks did your household take out recycling waste in grey (or green) bags for door to door collection?" This was followed by a question on respondent recall of household uptake of the scheme as at 2008. "Now think back to how long ago your household started using these recycling services. When did your household start using grey bags? These were introduced in 2008”. Respondents were also asked to estimate the weight of their weekly waste generated. The next set of questions gauged respondent agreement on a 0-10 Likert scale with statements, including "The waste that households separate is well managed by collectors" (to measure efficacy belief) and "I consider myself to be an environmentalist" (replicating Viscusi, et al 2011, to measure environmental motive); For political questions, the study employed Eurobarometer and European Value Surveys wording (GESIS 2008, European Commission 2012). For interest 
respondents were asked "How interested would you say you are in politics? Would you say you (personally) are very interested, quite interested, not very interested or not interested at all?" Ideology was gauged by left-right political orientation which accords with several other more complex characterisations (Jost, et al 2009), and has been employed in recent economic studies (Torgler and García-Valiñas 2007): "In politics, people sometimes talk of left and right. On a scale from 1 to 10, where 1 means left and 10 means right, where would you place, on this scale, generally, your views?" To gauge psychological attachment (Marsh 2006), respondents were asked "Which of these political parties do you feel closer to or less distant from? Partit Nazzjonalista, Partit Laburista, Alternattiva Demokratika, Other, Don't Know, Prefer Not to Answer; followed by "How close do you feel to this party, do you feel very close, somewhat close or not very close?"

\subsection{Experiment design}

While the survey generated data on actual participation, an embedded experiment was designed to examine intent to participate in a scheme and the effect of a political prime associating this with the new government. The study described a hypothetical recycling scheme and randomised respondents (equally) into one of two conditions. In the treatment condition, ahead of the description of the scheme, respondents were told "The Labour Party is now in government". In the control condition respondents received no such statement. In both treatments, respondents were then told "Imagine that a new door-to-door waste collection system is introduced in the coming days. In this new system, recyclable waste like plastic, paper, cardboard and tin, would continue to be collected in the transparent grey bags. These would be distributed for free. But garbage would only be collected door-to-door if it is placed 
in a special brown bag. The brown bags would cost 10 cents each." The attributes of the scheme in the scenario were deliberately realistic, almost identical to the current scheme. No further information was given to respondents on the consequences of their decisions, to avoid confounding results (Boudreau and MacKenzie 2014). Respondents were then asked to consider intent to participate in a scheme that incentivises recycling: "In the 10 weeks that follow, would your household be (a) likely to do or (b) likely to not do the following: Dispose of household garbage somewhere else; choose products that generate less waste; compost organic waste at home; separate some waste for recycling; other". Consideration of other waste management options were included in order to help respondents make more accurate predictions.

\subsection{The Sample}

As indicated in Figure 2, the sample was regionally representative. Sample respondents also report the same mean household size as the national population (2.9) and a gross income mean that was just slightly lower $(€ 22,631)$ than the corresponding figure from the National Statistics Office $(€ 25,800)$ (National Statistics Office 2012b). Respondents estimated very similar amounts of daily kerb-side waste as recorded in national estimates $(0.7$ kilograms per person) (National Statistics Office Malta 2013). Although no national figures are available to identify the percentage of households that participated in the kerb-side scheme, indications from other studies suggest that as at 2011, at least half of Maltese households were recycling regularly, and several more less regularly (Bezzina and Dimech 2011). Two years later, this study indicates that three-quarters of all households were participating to some degree or other in kerb-side recycling. Sampled household recycling rates stood on average at some 23 per 
cent, well within the total potential kerb-side recovery, estimated at 33 per cent (National Statistics Office Malta 2013). The percentage of respondents stating they voted Labour in the sample stood at 54, which corresponds to the percentage in the 2013 elections (Department of Information 2013). The data set also reveals that approximately half of the respondents stated that "felt close" to one of the two main parties. Analysis of cross-tabulations reveals expected correlations between voting outcomes and political attachment. In contrast with population at large, partisans are generally more likely to reside in the Northern regions of Malta (Nationalist) and in the South (Labour), and are less likely to hold tertiary education.

\section{Analysis}

\subsection{Hypotheses}

This data-set makes it possible to empirically test whether the likelihood of participation (actual and intended) in a government-promoted recycling scheme is higher among households with strong positive attachment towards the party in government and lower among households with strong positive attachment to the party in opposition.

More specifically, we set out to test whether uptake of a public-good scheme is positive in attachment to the party in government (Hypothesis 1). We do this by testing H1a: Uptake of a scheme launched by the Nationalist Party is higher among households attached to the Nationalist party; and H1b: Intent to take up a hypothetical scheme launched by the Labour Party is higher among households attached to the Labour party. We also test whether uptake of a public-good scheme is negative in attachment to the party in opposition (Hypothesis 2). We do this by testing H2a: Uptake of a scheme launched by the Nationalist Party is lower among 
households attached to the Labour party; and H2b: Intent to take up a hypothetical scheme launched by the Labour Party is lower among households attached to the Nationalist party. Finally, we examine whether the effect of political attachment is positive in links associating the scheme with the party in government (Hypothesis 3). We do this by testing: H3a. The effect of political attachment on uptake intent is stronger when respondents are primed with a political statement; and $\mathrm{H} 3 \mathrm{~b}$ : The effect of political attachment decays with distance from scheme promotion. To test each of these hypotheses we start by examining simple differences in means.

\subsection{Analysis of differences in means}

As can be seen in Figure 3, the data reveals that mean recycling participation doubled between the first year $($ Mean $=0.413, S . D .=0.493)$ and the end of the fifth $($ Mean $=0.772$, S.D. $=0.420$ ). Intent to recycle in the new scheme (that incentivises recycling) was almost unanimous $($ Mean $=0.938$, S.D. $=0.242)$. The averages also reveal that initial uptake was significantly lower $(p=0.032)$ among households closer to the Labour Party (Mean $=0.324$, S.D. $=0.469)$, in the first year of roll-out of the scheme, in contrast with households that considered themselves closer to the Nationalist party $($ Mean $=0.427$, S.D. $=0.496)$. By the fifth year of operation of the scheme, there was no significant difference in means. Nor was there any difference in intent.

To test Hypothesis 1, we first look at the mean rates of uptake of the scheme launched under a Nationalist government by Nationalist-attached households compared to the mean household. We then look at the mean uptake of a (hypothetical) scheme under a Labour government by Labour-attached households and compare this to the mean. In neither case do 
we find any significant differences: Those who signalled feeling "closer to" the Nationalist party $($ Mean $=0.427$, S.D. $=0.496)$ were no more likely $(p=0.330)$ to have taken up recycling than others $($ Mean $=0.408, S . D .=0.492)$ in the first year of the (Nationalist government $)$ scheme. Likewise, in the case of a hypothetical scheme launched under a newly elected Labour Party, those stating they were "closer to" Labour $($ Mean $=0.924$, S.D. $=0.266)$, were not more likely than others $($ Mean $=0.943$, S.D. $=0.234)$, to take up the scheme $(p=0.848)$. On the basis of this, we conclude that, contrary to our first hypothesis, attachment to the party in government does not seem to create a significant positive pressure on cooperation in a government promoted scheme.

To test Hypothesis 2, we examine the uptake rates of the scheme launched under a Nationalist government by Labour-attached households as well as rates of uptake of a new scheme under a Labour government by households attached to the Nationalist party. We find evidence that attachment to the party in opposition may suppress cooperation: In the first year of the scheme's launch there was a significantly lower $(P<0.001)$ uptake among those who stated they were "closer to" Labour $($ Mean $=0.324$, S.D. $=0.469)$ as opposed to others $($ Mean $=0.447$, S.D. $=0.486)$. On this basis we do not reject H2a. However in examining the difference in mean intent to participate in the new hypothetical scheme under a Labour government, we find no significant difference $(p=0.399)$ in intent between those "closer to" the Nationalist party $($ Mean $=0.933$, S.D. $=0.252)$ and others $($ Mean $=0.938$, S.D. $=0.241)$. We conclude that uptake of a public-good scheme may be is negative in attachment to the party in opposition. 
To test Hypothesis 3, we exploit the randomisation of the prime/no-prime treatment with a political cue that associates the public-good scheme with the Labour party. We find that administering a prime among the Labour attached ("closer to", "very close to" or "voted for" Labour) creates no significant increase in mean uptake (Primed Mean $=0.917$, S.D. $=0.276$, $($ Unprimed Mean $=0.931$, S.D. $=0.255),(p=0.663) .{ }^{2}$ But among those "closer to" the Nationalist party, administering a prime significantly $(P=0.021)$ suppresses uptake (Primed Mean $=0.897$, S.D. $=0.306 ;$ Unprimed Mean =0.974, S.D. $=0.160)$, as depicted in Figure 4. It appears then, that the prime does create an effect, but only in the negative direction, among those close to the party in opposition. Furthermore, there is no evidence that households intended to stop recycling: What the prime seems to do is to suppress intent to start. Turning to $\mathrm{H} 3 \mathrm{~b}$, it seems clear from Figure 3 that distinctions based on partisan attachment are no longer present five years after the initial promotion of the scheme. Indeed, in contrast with what was observed in Year 1, those close the Labour party $($ Mean $=0.763$, S.D. $=0.426)$, were no less likely $(p=0.325)$ than others $($ Mean $=0.777, S . D .=0.417)$ to be recycling later in the scheme's life. On the basis of these results, we do not reject Hypothesis 3.

Figure 3 Recycling participation among politically attached, all households Figure 4 Effect of a prime on recycling intent among politically attached, all households

\subsection{Formal analysis}

\footnotetext{
${ }^{2}$ We cannot exclude that the possibility that the absence of a positive effect of the prime may be due to the very high levels of intent signaled among both the primed and unprimed Labour voters, leaving little room for significant differences to be registered.
} 
In order to test whether these findings survive ceteris paribus conditions, we now set about a more formal analysis of the role of political attachment. Drawing upon the conceptual framework outlined in Section 2, and following others in the field (e.g. Briguglio et. al 2015, Callan and Thomas 1997, Hage and Soderholm 2008) we specify the likelihood of participation in a recycling scheme as a function of household constraints, scheme attributes, environmental preferences and demographic controls. We add partisan preferences, whose effect we are interested in testing, as per Model 1:

$Y_{i}=\alpha+\beta 1 G_{i}+\beta 2 C_{i}+\beta 3 E_{i}+\beta 5 D_{i}+\beta 5 P_{i}+u_{i}$

Model 1

Where

$\mathrm{i}$ indexes households;

$\mathrm{Y}_{\mathrm{i}}$ is the likelihood of waste separation by household $\mathrm{i}$;

$\mathrm{G}_{\mathrm{i}}$ is a vector of scheme attributes enjoyed by household $\mathrm{i}$

$\mathrm{C}_{\mathrm{i}}$ is a vector of constraints faced by household $\mathrm{i}$, including income, time and space;

$\mathrm{E}_{\mathrm{i}}$ is a vector describing household i's pro-environmental and ideological preferences;

$D_{i}$ is a vector of demographic controls

$\mathrm{P}_{\mathrm{i}}$ is a vector describing household i's partisan preferences

$\mathrm{u}_{\mathrm{i}}$ represents the error term.

Within this framework, and in line with the findings of the literature, we expect the chances of observing recycling (Y) to be lower among households with higher constraints (C), higher among those with pro-environmental preferences (E) and higher among those enjoying 
favourable scheme attributes $(\mathrm{G})$. The main test of interest is whether the likelihood of uptake (Y) is higher among households with strong positive attachment towards the party in government, and lower among households with strong positive attachment to the party in opposition, even after controlling for ideology and political interest. In estimating the model with intent to participate as the outcome variable, we include recycling experience as an important control variable (Knussen and Yule 2008). Here we are also able to test how a political prime interacts with partisan preferences, anticipating higher intent among primed households with strong positive attachment towards the party in government and lower intent among primed households with strong positive attachment to the party in opposition.

\section{Table 1 Determinants of recycling participation, Survey data}

Table 1 provides the descriptive statistics for the variables employed in the analysis. The intervention vector $(\mathrm{G})$ is represented by the variables COLLECT-REC, COLLECT-MIX, FREE-BAGS and INFO-TYPES, measuring perceived frequency of collection of recycling and mixed waste per week, availability of free recycling bags, and the number of information sources which the household uses (Council, Government, Operator). The variable USES-SITE captures the extent to which the household uses alternative recycling disposal facilities, which theoretically could compete with participation in the kerb-side scheme (Beatty, et al 2007). The vector of household constraints $(\mathrm{C})$ is represented by the variables SPACE, SINGLE and WASTE, the first indicating whether the residence has a garden or not, the second identifying households with only one resident (as a measure of adult time available for recycling), the third indicating kilograms of waste generated as estimated by the survey respondent, which we consider exogenous. Pro-environmental sentiment $(\mathrm{E})$ is captured by two variables PRO-ENV 
and EFFICACY, both on a 0 to 10 scale, indicating the respondents' agreement with the relevant statements. Other control variables include FEMALE, AGE and EDUC which capture the respondent's gender, age and educational levels respectively. YEARS is a control variable, useful in analysis of intent and measuring years of recycling to date.

The main variables of interest, ATTACH-PN and ATTACH-PL, measure attachment where respondents stating they feel "closer" to the Nationalist Party and the Labour Party are coded as (1) respectively and (0) otherwise. For use in the intent analysis, the variable PRIME represents a simple binary variable of whether or not the respondent received a prime, and the variables $\mathrm{P}^{*}$ represent the interaction of the prime with the attachment variables. At the risk of over-specification, but with a view to parsing out the pure effects of attachment, the variables INTEREST and IDEOLOGY control for political interest and political ideology respectively, the former on a four-point scale, the latter on a 10-point scale, while the variables VOTE capture voting outcomes. The dependent variable is represented by UPTAKE, PARTICIPATES, and INTENT, indicating respectively whether households took up participation in the kerb-side scheme in 2008 and by 2013 and whether they intended to participate in the new scheme.

\section{Table 2 Determinants of recycling uptake}

Table 2 reports the determinants of uptake at the start of the scheme introduced and promoted by Nationalist government, (UPTAKE) as the dependent variable. Given that the dependent variables are binary, and that Ordinary Least Squares estimation can run into the problem of generating predictions that are not bound between zero and one, we employ a Probit 
link function to estimate the models for uptake and participation. Here, the inverse standard normal distribution of the probability (of uptake) is modelled as a linear combination of the predictors. In Table 2 we report the marginal effects, that is the increase in probability attributed to a one-unit increase in each of the predictors for an average individual (dy/dx). The table also includes the standard errors of the individual coefficients, and the main fit-statistics.

Ahead of interpreting the results, it bears emphasis here that the predicted variable in Table 2 is one that is based on recall. Furthermore several of the explanatory variables are essentially proxies. Indeed we employ the 2013 data for preferences and constraints, relying on the assumption that these provide an adequate proxy of those in 2008. Both 2008 and 2013 were election years and political ideology and attachment tend to be stable preferences. We also include variables that describe scheme attributes in 2013, in place of those which may have been present in 2008, while exerting due caution in interpretation - essentially we include these variables as control variables with a view to capturing some of the variation that characterized the initial scheme attributes.

We first estimate a simple model (Model a) without political determinants. As expected, we find that the availability of physical space in a household positively contributed to uptake, as did pro-environmental attitudes and education levels. Females also had a stronger tendency to report uptake in 2008. Single person households tended to report lower 2008 uptake, as theoretically anticipated, as did the use of alternative recycling schemes. We find that scheme attributes (proxied by those in 2013) provide little explanatory power, other than a negative coefficient on the variable describing information sources - suggesting that the more varied the sources of information (as at 2013), the lower the uptake at 2008. 
We then proceed to include the VOTE variable (Model b). We find that households which voted Labour (in 2013) were less likely to be recycling at the scheme's launch in 2008 (testing the model with 2008 recalled vote returns the same result, albeit with a smaller sample size). Because VOTE captures many dimensions which may not always operate in the same direction, we then replace VOTE by separate variables capturing political interest, ideology and attachment, in order to see which dimension of voting outcome may be responsible for driving these results (Model c). We find that neither political interest nor ideology (both proxied by 2013 values) help explain 2008 uptake. Rather, it is political attachment (and only that towards the Labour party) which constitutes a significant (and negative) determinant. The computed marginal effects suggest that when respondents admitted to being "Closer to" to the Labour party, the probability of uptake of the scheme was reduced by 7 percent, even after controlling for other drivers (including environmental morality) and constraints. But being closer to the nationalist party does not constitute a significant determinant. The results remained stable when the model was estimated using LOGIT, REG and VCE (ROBUST) commands. $^{3}$

\section{Table 3 Determinants of recycling participation}

In Table 3, the same process is repeated, this time with eventual participation (PARTICIPATES) in an established scheme as the depenedent variable. Once again, the first

\footnotetext{
${ }^{3}$ We also estimate a model with years of participation in the kerbside scheme as the dependent variable. We again confirm that being close to the Labour Party delays uptake of a scheme run under a Nationalist government. The coefficient here is 0.522 (significant at the $5 \%$ level) suggesting that attachment to the Labour Party creates a 6 month delay, ceteris paribus.
} 
model (Model a) is estimated without political determinants. The results again confirm theoretical expectations: Households are more likely to recycle when their members hold higher environmental moral motives and efficacy beliefs. Households are less likely to recycle when they face constraints like limited space, few members and limited waste, and they are more likely to participate when scheme attributes, (including frequency of collection and free bags) make it easier to do so. As expected, the use of competing schemes reduces the chances of taking up kerb-side recycling. We then add political variables, starting with the variable VOTE (Model b), which provides no additional explanatory power. We replace this variable by INTEREST, IDEOLOGY and ATTACH to capture the possible role of the distinct political preferences in the full model (Model c). We find that distinctions in political (left/right) ideology do not add any additional explanatory power, and neither do distinctions in political attachment. These findings confirm the results of the simple analysis of means. We also observe, a greater chance of recycling participation among households where the respondent holds stronger political interest.

\section{Table 4 Determinants of recycling intent}

Finally, Table 4 summarises the determinants of participation intent (INTENT) in a hypothetical recycling scheme, employing the data generated by the embedded experiment. It is worth recalling, at this stage, that the scheme is identical to the current scheme in every way, except that the scheme incentivises recycling by having residents pay a nominal fee to dispose of remaining (unseparated) waste. Few respondents admitted to having no intent to participate in this scheme, limiting the variation in the dependent variable. Nonetheless, we start by estimating INTENT to participate in a hypothetical scheme as a simple function of years of 
participation in the current scheme, on the premise that hypothetical kerbside recycling scheme is determined by experience in recycling (Knussen and Yule 2008). We control only for the difference in attributes between the current and the new scheme (Frey and Oberholzer-Gee 1997) as well as basic respondent demographics (Model a). We note that both experience with recycling and the provision of free recycling bags in the current scheme positively effect intent to participate in a scheme where recycling will effectively be subsidised. We then include VOTE as an explanatory variable, but find that this adds no predictive power (Model b). We proceed to replace VOTE by incorporating IDEOLOGY, INTEREST and ATTACHMENT (Model c), and find, again, no further explanatory power on the intent to participate in the scheme. Next, we control for the effect of the prime and its interaction with political attachment. Model d is fitted with STATA's regress command, given that the estimation of the magnitude, sign and statistical significance of interaction effects in nonlinear models is problematic (Ai and Norton 2003). ${ }^{4}$ Now find that being politically-attached to the Nationalist Party and being reminded that the Labour Party is in government may suppresses intent to participate. Once again, however, it is, if anything, those who declare themselves to be close to the party in opposition whose intent is influenced (negatively), and not those who declare themselves closer to the party in government.

By way of summary, the results show that attachment to the Labour Party in opposition, was a significant, negative determinant of initial uptake of the Nationalist government scheme. There is also evidence that attachment with the Nationalist party in opposition interacts with a

\footnotetext{
${ }^{4}$ A comparison of the outcomes with a Probit estimation corrected for the magnitude of interaction effect using the "inteff" command (Norton, et al 2004), shows consistent results: the interaction of the prime with attachment to the party in opposition suppressed uptake.
} 
partisan cue to suppress intent to participate in a hypothetical scheme under a Labour government. Neither attachment to the Nationalist Party nor attachment to the Labour Party were significant determinants of eventual participation in an established scheme. Reverting back to the original hypotheses, we can, once again, safely reject Hypothesis 1: Uptake at the launch of a government promoted scheme uptake is no higher among households attached to the party in government, whether in the context of an actual scheme (H1a) or of a hypothetical scheme (H1b). Once again, we do not reject Hypothesis 2: Uptake is lower among households attached to the party in opposition in the context of an actual scheme launched by the Nationalist Party (H2a) and in the context of a hypothetical scheme launched by the Labour party $(\mathrm{H} 2 \mathrm{~b})$. We again confirm that the effect of partisan attachment on intent is significant only in the presence of a partisan cue in the scheme's promotion and only among negative partisans (H3a). Moreover, the effect of partisan attachment decays over time and other determinants gain importance $(\mathrm{H} 3 b)$.

\subsection{Discussion}

A review of the main shortcomings of this study, and of the efforts made to mitigate them, will draw attention to the importance of further academic scrutiny on the question of the role of political attachment in determining uptake of public-good schemes. Although direct observation of household recycling is difficult and may influence behaviour itself (Brekke, et al 2010), an obvious concern with research such as this, is the reliance on self-reported behaviour which can be biased towards higher recycling reports. The use of telephone interviews (as opposed to self-administered postal/web surveys) addressed some concern with selection bias. The insertion of face-saving questions, appeals to honesty, assurance of confidentially and anonymity (enumerators themselves did not know whom they were calling), 
and invitations to report behaviour in specific periods, were all intended to eliminate strategic responses. The resulting data were both internally consistent and closely comparable with national data.

A specific shortcoming of the data on initial uptake, was reliance on recall. In this regard, the results of the formal analysis of uptake (Table 2) merit particular caution, even if they do replicate those from a study which employed administrative data in the same context (Briguglio, et al 2015). A similar issue lay in relying on stated intent for future uptake, which implicitly rests on the assumption that intent is an antecedent to behaviour (Ajzen 1991), or at least, that the intent-behaviour bias is evenly spread. Lack of sincerity, poor forecasting (Tourangeau, et al 2000) and lack of control over other household members (Boldero 1995) could introduce unobserved heterogeneity among the respondents. To mitigate other errors, and in line with best practice, respondents were given the opportunity to reflect not only upon their current behaviour but also on other waste disposal options before being asked to consider future recycling behaviour (Arrow, et al 1993). They were offered a realistic scenario with a significant likelihood of being implemented (Poe and Vossler 2011), and were, reasonably, asked to predict their behaviour over the coming weeks. It was also fortunate, that in most instances, respondents stated that they were the household member responsible for waste. Future research that observes (rather that relies on recall or intent) the same individuals over time would mitigate some of these shortcomings.

In the experimental component, we took care to meet the criteria for sound design and analysis (Gaines, et al 2007). We employed a very simple treatment in stripped-down settings with no deception and no cash reward (McDermott 2002). A legitimate question is whether the 
prime represented the kind of cue respondents may receive in real-life scenarios, or whether this was a relatively stronger stimulus, given that survey respondents are a captive audience (Luskin, et al 2002; Druckman and Nelson 2003). To mitigate this, the prime administered was very subtle and only implicitly politicised the scheme. It was free of the political posturing and repetition, which may occur in real life. Indeed, if anything, real-life stimuli could be stronger. Another oft-made consideration is whether the prime induces respondent learning (Lenz 2009). This is hardly likely to have been the case, given that the prime only mentioned that the Labour party was in government. With a 93 per cent voting turnout in the election held a few months earlier, it is unlikely that any of the respondents did not already know that. In fact, one problem with the treatment is that have been that the perception of the control (un-primed) group may not have been sufficiently different from that of the primed group. Together, these considerations suggest that the results in the intent scenario may actually be lower-bound estimates. Future research that tests the effects on cooperation of administering stronger cues on partisan preferences could develop these findings further.

Other issues with the formal estimation methods are common to the techniques employed, but bear mention for the sake of completeness. In specifying a formal model, there is a risk of omitted variables, which can result in biased variable coefficients or errors. The specification of the models employed here, based on a conceptual framework of utility maximisation under constraints, included variables typically employed in recycling models within the limitations posed by over-specification. In fitting the models with a standard probit model, we also assumed homoskedasticity of the errors in the latent-variable model. To address possible problems with this assumption we also compute robust standard errors and reestimated the models using Logit and Ordinary Least Squares techniques. The results survived 
these tests. The fact that the results on the other, more established determinants of recycling cooperation (namely household constraints, enabling scheme attributes and pro-envrionmental motives) support those in the environmental economics literature (Briguglio 2016), lends greater confidence to the more novel findings of our study, namely those pertaining to partisanship.

\section{Conclusion}

The findings in this study contribute new theoretical insights on the question that the study set out to examine, namely, whether political attachment is a significant determinant of participation in public-good scheme. Attachment to the party in opposition emerges as having a significant and negative influence on likelihood of participation in a government scheme, responding to cues that associate the scheme with the party in government. Such association does not seem enhance uptake among those who are attached to the party in government, and decays over time. This asymmetry reflects that which is observed when political ideology interacts with framing (McBeth, et al 2013; Costa and Kahn 2013), or with news interest (Coffey and Joseph 2013), and when vote interacts with promotional effort (Briguglio, et al 2015).

In some ways the results are unsurprising, echoing the observed phenomenon that the way economic performance is perceived, depends on voters' partisan allegiance and the party in power (Schwartz 2017), and reflecting conventional wisdom that favorability towards a policy becomes more partisan the stronger its link with a particular party. Yet these findings provide some direct evidence that partisan allegiance can actually affect participation in a 
public programme. Indeed, the findings offer an important insight for promoting such publicgood schemes, in order to avoid creating unnecessary barriers. Strength of (negative) feeling towards politicians occurs well beyond the shores of Malta (Bartle and Bellucci 2009), not only in other, strongly bi-polar, two-party political systems (like the United Kingdom, USA, and Spain) but also in polarised multi-party or cadre party systems. In such contexts, governments wishing to encourage voluntary cooperation would do well to avoid partisan messages, or messengers, when promoting a scheme. Delaying political point-scoring to a later point (once the scheme is taken up) could be one way to of limiting harmful impacts.

Voluntary contribution in public-good schemes is a phenomenon that is attracting increasing interest in economic literature (Guttman and Goette 2015, Guttman 2013), particularly given the (political, legislative and administrative) constraints of employing financial dis/incentives (Briguglio 2016). The findings of this study shed light on a determinant of voluntary cooperation which is quite distinct from other motives discussed in the literature to date. Moreover, if partisanship can influence household behaviour in a domain like the separation of waste at home, then there is scope to examine whether it also happens in other public-good domains. 


\section{Acknowledgments}

The study was funded through an Early Career Engagement Grant awarded by the Scottish Institute for Research in Economics and was supported by a University of Malta Bursary. Neither funder had any involvement in the study design, nor in the collection, analysis and interpretation of data, in the writing of the report, or in the decision to submit the article for publication.

\section{References}

Abbink K. and Sadrieh A., 2009. The pleasure of being nasty. Economics Letters, 105:306308.

Abbott A., Nandeibam S. and O'Shea L., 2013. Recycling: Social norms and warm-glow revisited. Ecological Economics, 90:10-18.

Ahn, T.K., Ostrom, E. and Walker, J. 2010. A common-pool resource experiment with postgraduate subjects from 41 countries. Ecological Economics, 69:12, 2624-2633.

Ai C. and Norton E.C., 2003. Interaction terms in logit and probit models. Economics letters, 80:123-129.

Ajzen I., 1991. The Theory of Planned Behaviour. Organisational behavior and human decision processes, 50:179-211.

Andreoni J., 1990. Impure Altruism and Donations to Public Goods: A Theory of WarmGlow Giving. The Economic Journal, 100:pp. 464-477.

Arrow K., Solow R., Portney P.R., Leamer E.E., Radner R. and Schuman H., 1993. Report of the NOAA panel on contingent valuation. Federal Register, 58:4601-4614.

Baldacchino G., 2002. A nationless state? Malta, national identity and the EU. West European Politics, 25:191-206. 
Bartle J. and Bellucci P., 2009. Political parties and partisanship: Social identity and individual attitudes. Routledge.

Baumol, W.J. and Oates, W.E., 1988. The Theory of Environmental Policy. UK: Cambridge University Press.

Beatty T.K.M., Berck P. and Shimshack J.P., 2007. Curbside recycling in the presence of alternatives. Economic inquiry, 45:739-755.

Bezzina F.H. and Dimech S., 2011. Investigating the determinants of recycling behaviour in Malta. Management of Environmental Quality: An International Journal, 22:463-485.

Biel, Anders, and Thøgersen John, 2007 Activation of social norms in social dilemmas: A review of the evidence and reflections on the implications for environmental behaviour." Journal of economic psychology 28.1 (2007): 93-112.

Boissevain J., 1993. Saints and Fireworks:Religion and Politics in Rural Malta. Progress Press, Malta.

Boldero J., 1995. The prediction of household recycling of newspapers: The role of attitudes, intentions, and situational factors. Journal of Applied Social Psychology, 25:440462.

Bolsen, T., Druckman J.N., Cook F.L. 2014. The Influence of Partisan Motivated Reasoning on Public Opinion Political Behavior 36(2): 235-262.

Bolsen T., Ferraro P.J. and Miranda J.J., 2014. Are Voters More Likely to Contribute to Other Public Goods? Evidence from a Large-Scale Randomized Policy Experiment. American Journal of Political Science, 58:17-30. 
Boudreau C. and MacKenzie S.A., 2014. Informing the electorate? How party cues and policy information affect public opinion about initiatives. American Journal of Political Science, 58:48-62.

Brekke K.A., Kipperberg G. and Nyborg K., 2010. Social Interaction in Responsibility Ascription: The Case of Household Recycling. Land Economics, 86:766-784.

Brekke K.A., Kverndokk S. and Nyborg K., 2003. An economic model of moral motivation. Journal of Public Economics, 87:1967-1983.

Briguglio, M. 2016 Household Cooperation In Waste Management: Initial Conditions And Intervention. Journal of Economic Surveys

Briguglio M., 2009. Politics, the State and Civil Society - A Theoretical Framework. In: J. Cutajar and G. Cassar (Editors), Social Transitions in Maltese Society. Agenda, Malta, pp. $125-146$.

Briguglio, M.; Delaney L., and Wood A. 2015. Voluntary recycling despite disincentives. Journal of Environmental Planning and Management: 1-24.

Bruvoll A. and Nyborg K., 2004. The Cold Shiver of Not Giving Enough: On the Social Cost of Recycling Campaigns. Land Economics, 80:539-549.

Callan, S. J., and Thomas J.M 1997. The impact of state and local policies on the recycling effort." Eastern Economic Journal 23.4: 411-423.

Campbell A., Converse P.E., Miller W.E. and Stokes D.E., 1960. The American voter. New York and London: John Wiley \& Sons, Inc. 
Coffey D.J. and Joseph P.H., 2013. A Polarized Environment The Effect of Partisanship and Ideological Values on Individual Recycling and Conservation Behavior. American Behavioral Scientist, 57:116-139.

Costa D.L. and Kahn M.E., 2013. Energy conservation "nudges" and environmentalist ideology: Evidence from a randomized residential electricity field experiment. Journal of the European Economic Association, 11:680-702.

Crewe I., 1976. Party identification theory and political change in Britain. Party identification and beyond. London: Wiley:33-61.

Croson, R, and Treich R. 2014. Behavioral environmental economics: promises and challenges. Environmental and Resource Economics 58.3: 335-351.

Czajkowski M., Kądziela T. and Hanley N., 2014. We want to sort! Assessing households' preferences for sorting waste. Resource and Energy Economics, 36:290-306.

Druckman, J. N., Kuklinski, J. H., and Sigelman, L. 2009. The unmet potential of interdisciplinary research: Political psychological approaches to voting and public opinion. Political Behavior, 31(4):485-510

Druckman J.N. and Nelson K.R., 2003. Framing and deliberation: How citizens' conversations limit elite influence. American Journal of Political Science, 47:729-745.

Dupont D.P. and Bateman I.J., 2012. Political affiliation and willingness to pay: An examination of the nature of benefits and means of provision. Ecological Economics, 75:43-51.

Frey B.S. and Oberholzer-Gee F., 1997. The Cost of Price Incentives: An Empirical Analysis of Motivation Crowding-Out. American Economic Review, 87:746-755. 
Fullerton D., Leicester A. and Smith S., 2010. Environmental Taxes. In: J. Mirrlees (Editor), Tax by Design: The Mirrlees Review. Oxford University Press, Ch 5.

Gaines B.J., Kuklinski J.H. and Quirk P.J., 2007. The logic of the survey experiment reexamined. Political Analysis, 15:1-20.

Gerber A.S. and Huber G.A., 2010. Partisanship, political control, and economic assessments. American Journal of Political Science, 54:153-173.

Glaeser E.L., 2014. The Supply of Environmentalism: Psychological Interventions and Economics. Review of Environmental Economics and Policy, 8:208-229.

Graber D.A. and Smith J.M., 2005. Political communication faces the 21st century. Journal of Communication, 55:479.

Green D.P., Palmquist B. and Schickler E., 2004. Partisan hearts and minds: Political parties and the social identities of voters. Yale University Press.

Guttman, J.M., Goette, L. (2015) Reputation, volunteering, and trust: Minimizing reliance on taste-based explanations, European Journal of Political Economy 40:375-386

Guttman, J.M. (2013) On the evolution of conditional cooperation European Journal of Political Economy 30: 15-34

Hage O. and Söderholm P., 2008. An econometric analysis of regional differences in household waste collection: The case of plastic packaging waste in Sweden. Waste Management, 28:1720-1731.

Hage O., Söderholm P. and Berglund C., 2009. Norms and economic motivation in household recycling: Empirical evidence from Sweden. Resources, Conservation and Recycling, 53:155-165. 
Halvorsen B., 2008. Effects of Norms and Opportunity Cost of Time on Household Recycling. Land Economics, 84:501-516.

Heyman J. and Ariely D., 2004. Effort for Payment. Psychological Science (WileyBlackwell), 15:787-793.

Jenkins R.R., Martinez S.A., Palmer K. and Podolsky M.J., 2003. The determinants of household recycling: a material-specific analysis of recycling program features and unit pricing. Journal of Environmental Economics and Management, 45:294-318.

John P., 2013. All tools are informational now: How information and persuasion define the tools of government. Policy \& Politics, 41:605-620.

Jost J.T., Federico C.M. and Napier J.L., 2009. Political ideology: Its structure, functions, and elective affinities. Annual Review of Psychology, 60:307-337.

Hahn, R.W. 1989. Economic Prescriptions for Environmental Problems: How the Patient Followed the Doctor's Orders. The Journal of Economic Perspectives, 3.2: 95-114.

Katz, R. S. 1987 Party Government and Its Alternatives/Richard S. Katz. Future of Party Government: Party Governments-European and American Experiences, edited by Richard S. Katz.-Berlin: Walter de Gruyter, 1-25.

Kinnaman T.C. and Takeuchi K., 2014. Handbook on Waste Management. Edward Elgar Publishing.

Kinnaman T.C., 2006. Policy watch: examining the justification for residential recycling. The Journal of Economic Perspectives, 20:219-232.

Knussen C. and Yule F., 2008. I'm Not in the Habit of Recycling. Environment and Behavior, 40:683-702. 
Lane J. 2009 Elections in Malta: The Single-Transferable-Vote System in Action, 1921 2009, Available: http://www.maltadata.com. [Accessed 1.4.2016]

Lange F., Brückner C., Kröger B., Beller J. and Eggert F., 2014. Wasting ways: Perceived distance to the recycling facilities predicts pro-environmental behavior. Resources, Conservation and Recycling, 92, 246-254.

Lenz G.S., 2009. Learning and opinion change, not priming: Reconsidering the priming hypothesis. American Journal of Political Science, 53:821-837.

Lerman, A., Sadin, M., and Trachtman, S. (2017) Policy Uptake as Political Behavior: Evidence from the Affordable Care Act. American Political Science Review 111(4):755770

Lewis-Beck, M., Nadeau R., Elias A. 2008 Economics, party, and the vote: Causality issues and panel data. American Journal of Political Science 52, 1: 84-95

Luskin R.C., Fishkin J.S. and Jowell R., 2002. Considered opinions: Deliberative polling in Britain. British Journal of Political Science, 32:455-487.

Marsh M., 2006. Party identification in Ireland: An insecure anchor for a floating party system. Electoral Studies, 25:489-508.

McBeth M.K., Lybecker D.L. and Kusko E., 2013. Trash or Treasure: Recycling Narratives and Reducing Political Polarisation. Environmental Politics, 22:312-332.

McDermott R., 2002. Experimental methods in political science. Annual Review of Political Science, 5:31-61.

Neumayer E., 2004. The environment, left-wing political orientation and ecological economics. Ecological Economics, 51:167-175. 
Norton E.C., Wang H. and Ai C., 2004. Computing interaction effects and standard errors in logit and probit models. Stata Journal, 4:154-167.

OECD, 2008. Household Behaviour and the Environment: Reviewing the Evidence. OECD Publications, France.

Poe G.L. and Vossler C.A., 2011. Consequentiality and contingent values: an emerging paradigm. The international handbook on non-market environmental valuation:122-141.

Schultz P.W., Nolan J.M., Cialdini R.B., Goldstein N.J. and Griskevicius V., 2007. The Constructive, Destructive, and Reconstructive Power of Social Norms. Psychological Science (Wiley-Blackwell), 18:429-434.

Schwartz S.H., 1977. Normative Influences on Altruism. Advances in experimental social psychology, 10:221-279.

Sidique S.F., Joshi S.V. and Lupi F., 2010. Factors influencing the rate of recycling: An analysis of Minnesota counties. Resources, Conservation and Recycling, 54:242-249.

Sunstein, Cass R. (2015) Partyism, University of Chicago Legal Forum: Vol. 2015 , Article 2. Available at: http://chicagounbound.uchicago.edu/uclf/vol2015/iss1/2 [Accessed 4.7.2017]

Thaler R.H. and Sunstein C.R., 2008. Nudge: Improving decisions about health, wealth, and happiness. Yale Univ Press.

Torgler B. and García-Valiñas M.A., 2007. The determinants of individuals' attitudes towards preventing environmental damage. Ecological Economics, 63:536-552.

Tourangeau R., Rips L.J. and Rasinski K.A., 2000. The psychology of survey response. Cambridge University Press. 
Turner, J.C. 1985 Social categorization and the self-concept: A social cognitive theory of group behavoir. Lawler, E. J., ed. Advances in group processes: Theory and research (Greenwich, CT: JAI press2: 77-122.

Tversky A. and Kahneman D., 1986. Rational Choice and the Framing of Decisions. The Journal of Business, 59:251-278.

Valle D., Oom P., Rebelo E., Reis E. and Menezes J., 2005. Combining Behavioral Theories to Predict Recycling Involvement. Environment and Behavior, 37:364-396.

Viscusi W.K., Huber J. and Bell J., 2011. Promoting Recycling: Private Values, Social Norms, and Economic Incentives. American Economic Review, 101:65-70.

Wakefield S.E., Elliott S.J., Eyles J.D. and Cole D.C., 2006. Taking environmental action: the role of local composition, context, and collective. Environmental Management, 37:4053.

\section{Web sources}

Department of Information, 2013. General \& Local Councils' Elections 2013: Notices by Electoral Commission. Retrieved on 1.4.2016 https://www.gov.mt/en/Government/Press\%20Releases/Pages/2013/March/01/pr0319.asp $\underline{\mathrm{x}}$

European Commission, 2012. Standard Eurobarometer 77: Public Opinion in the EU $\underline{\text { Retrieved on 1.4.2016 http://ec.europa.eu/public_opinion/archives/eb/eb77/eb77_en.htm }}$ European Environment Agency, 2013. Managing municipal solid waste - a review of achievements in 32 European countries 2/2013. Retrieved on 1.4.2016. http://www.eea.europa.eu/publications/managing-municipal-solid-waste 
GESIS, 2013. European Values Study, 2008. Retrieved on 1.4.2016

http://www.gesis.org/en/services/data-analysis/survey-data/european-values-study/

$\underline{\text { IDEA (International Institute for Democracy and Electoral Assistance), 2004. Voter }}$

Turnout in Western Europe. Retrieved on 1.4.2016

http://www.idea.int/publications/voter_turnout_weurope/upload/Full_Reprot.pdf

National Statistics Office, 2012a. Census of Population and Housing 2011: Preliminary

Report. Retrieved on 1.4.2016

http://www.nso.gov.mt/statdoc/document_file.aspx?id=3424

National Statistics Office, 2012b. Statistics on Income and Living Conditions 2010.

Retrieved on 1.4.2016 http://www.nso.gov.mt/site/page.aspx?pageid=346

$\underline{\text { National Statistics Office Malta, 2013. News Release: Solid Waste Management in Malta }}$ $\underline{2004-2011 \text { Retrieved on 6.8.2014 }}$

http://www.nso.gov.mt/statdoc/document_file.aspx?id=3500

Schwartz N.D. 2017 Boom or Bust: Stark Partisan Divide on How Consumers View

Economy in New York Times, April 82017 Retreived on June 222017

https://www.nytimes.com/2017/04/08/business/economy/the-picture-of-our-economylooks-a-lot-like-a-rorschach-test.html?_r=0 
Table 1: Determinants of recycling participation (Survey data)

\begin{tabular}{|c|c|c|c|c|}
\hline Variable & $\mathbf{N}$ & Mean & S.D. & Label \\
\hline \multicolumn{5}{|c|}{ Participation (Y) } \\
\hline PARTICIPATES & 987 & 0.772 & 0.420 & Household Recycles at Kerb, Year $5(0-1)$ \\
\hline UPTAKE & 965 & 0.413 & 0.493 & Household Recycled at Kerb, Year $1(0-1)$ \\
\hline INTENT & 946 & 0.938 & 0.242 & Intent to Separate Waste $(0-1)$ \\
\hline \multicolumn{5}{|c|}{ Perceived Scheme Attributes (G) } \\
\hline COLLECT-REC & 942 & 1.361 & 0.571 & Recycling Collection Frequency (0-6) \\
\hline COLLECT-MXD & 960 & 5.156 & 1.009 & Garbage Collection Frequency (0-7) \\
\hline FREE-BAGS & 988 & 0.370 & 0.483 & Free Bag Distribution (0-1) \\
\hline INFO-TYPES & 989 & 1.278 & 0.819 & Number of Information Sources (0-3) \\
\hline USES-SITE & 989 & 0.832 & 1.346 & Uses Bring-in sites for Disposal (0-5) \\
\hline \multicolumn{5}{|c|}{ Household Constraints (C) } \\
\hline SPACE & 989 & 0.378 & 0.485 & Household has a Garden $(0-1)$ \\
\hline SINGLE & 987 & 0.124 & 0.329 & One Person Household (0-1) \\
\hline WASTE & 899 & 14.913 & 15.43 & Estimated Total Kerb Waste Generated \\
\hline \multicolumn{5}{|c|}{ Environmental Preferences (E) } \\
\hline EFFICACY & 985 & 8.257 & 2.218 & Efficacy Belief (0-10) \\
\hline PRO-ENV & 984 & 6.456 & 2.845 & Considers Self Environmentalist (0-10) \\
\hline \multicolumn{5}{|c|}{ Demographic Controls (D) } \\
\hline FEMALE & 983 & 0.740 & 0.439 & Respondent is Female $(0-1)$ \\
\hline AGE & 979 & 53.402 & 15.87 & Respondent Age (18-90) \\
\hline EDUC & 971 & 3.231 & 1.023 & Respondent Level of Education (1-5) \\
\hline \multicolumn{5}{|c|}{ Political Preferences $(\mathbf{P})$} \\
\hline INTEREST & 982 & 2.257 & 0.948 & Political Interest (1-4) \\
\hline IDEOLOGY & 980 & 5.401 & 1.313 & Political Ideology, Left Right (1-10) \\
\hline PRIME & 989 & 0.5 & 0.5 & Treated with Prime \\
\hline ATTACH-PN & 975 & 0.171 & 0.377 & Attached to Nationalist Party $(0-1)$ \\
\hline ATTACH-PL & 975 & 0.290 & 0.454 & Attached to Labour Party $(0-1)$ \\
\hline VOTE PN & 975 & 0.144 & 0.351 & Reported Voting PN in 2013 \\
\hline VOTE PL & 975 & 0.275 & 0.447 & Reported Voting PL in 2013 \\
\hline \multicolumn{5}{|c|}{ Other Controls } \\
\hline YEARS & 965 & 3.482 & 2.560 & Years participating in Kerb- Scheme (0-6) \\
\hline YEARS-SITE & 973 & 2.875 & 4.432 & Years recycling at Site $(0-12)$ \\
\hline
\end{tabular}


Table 2: Determinants of initial recycling uptake

\begin{tabular}{|c|c|c|c|}
\hline MODEL & $\begin{array}{c}\text { a.Basic Df/dx } \\
\text { S.E. }\end{array}$ & $\begin{array}{c}\text { b. Vote Df/dx } \\
\text { S.E. }\end{array}$ & $\begin{array}{c}\text { c.Attach Df/dx } \\
\text { S.E. } \\
\end{array}$ \\
\hline \multirow[t]{2}{*}{ COLLECT-REC } & 0.033 & 0.032 & 0.035 \\
\hline & -0.031 & -0.031 & -0.031 \\
\hline \multirow[t]{2}{*}{ COLLECT-MXD } & 0.016 & 0.019 & 0.017 \\
\hline & -0.018 & -0.018 & -0.018 \\
\hline \multirow[t]{2}{*}{ FREE-BAGS } & $-0.058^{*}$ & -0.055 & -0.048 \\
\hline & -0.034 & -0.034 & -0.034 \\
\hline \multirow[t]{2}{*}{ INFO-TYPES } & $-0.055 * * *$ & $-0.050 * *$ & $-0.051 * *$ \\
\hline & -0.021 & -0.021 & -0.021 \\
\hline \multirow[t]{2}{*}{ USES-SITE } & $-0.042 * * *$ & $-0.036 * * *$ & $-0.037 * * *$ \\
\hline & -0.013 & -0.013 & -0.013 \\
\hline \multirow[t]{2}{*}{ SPACE } & $0.117 * * *$ & $0.112 * * *$ & $0.117 * * *$ \\
\hline & -0.034 & -0.034 & -0.034 \\
\hline \multirow[t]{2}{*}{ SINGLE } & -0.067 & $\begin{array}{c}-0.072 \\
\end{array}$ & $-0.087 *$ \\
\hline & -0.052 & -0.052 & -0.052 \\
\hline \multirow[t]{2}{*}{ WASTE } & $\mathbf{0}$ & 0 & $\mathbf{0}$ \\
\hline & -0.001 & -0.001 & -0.001 \\
\hline \multirow[t]{2}{*}{ EFFICACY } & 0.012 & 0.01 & 0.011 \\
\hline & -0.007 & -0.007 & -0.007 \\
\hline \multirow[t]{2}{*}{ PRO-ENV } & $\mathbf{0 . 0 5 0} * * *$ & $0.049 * * *$ & $0.052 * * *$ \\
\hline & -0.005 & -0.005 & -0.005 \\
\hline \multirow[t]{2}{*}{ FEMALE } & $0.069 *$ & 0.068* & 0.055 \\
\hline & -0.038 & -0.038 & -0.038 \\
\hline \multirow[t]{2}{*}{ AGE } & $\mathbf{0}$ & $\mathbf{0}$ & $\mathbf{0}$ \\
\hline & -0.001 & -0.001 & -0.001 \\
\hline \multirow[t]{2}{*}{ EDUC } & $0.048 * *$ & $0.040 * *$ & 0.038* \\
\hline & -0.019 & -0.02 & -0.02 \\
\hline \multirow[t]{2}{*}{ VOTEPN } & & -0.069 & \\
\hline & & -0.047 & \\
\hline \multirow[t]{2}{*}{ VOTEPL } & & $-0.093 * *$ & \\
\hline & & -0.038 & \\
\hline \multirow[t]{2}{*}{ INTEREST } & & & -0.012 \\
\hline & & & -0.019 \\
\hline \multirow[t]{2}{*}{ IDEOLOGY } & & & 0.007 \\
\hline & & & -0.012 \\
\hline \multirow[t]{2}{*}{ ATTACH-PN } & & & -0.022 \\
\hline & & & -0.044 \\
\hline \multirow[t]{2}{*}{ ATTACH-PL } & & & $-0.070 *$ \\
\hline & & & -0.04 \\
\hline $\mathbf{N}$ & $\mathbf{8 2 7}$ & 823 & 821 \\
\hline Log-Lik Intercept Only: & -561.833 & 588.66 & -556.906 \\
\hline Log-Lik Full Model: & -493.084 & -487.211 & -482.922 \\
\hline McFadden's Adj R2: & 0.09 & 0.092 & 0.09 \\
\hline Count R2: & 0.666 & 0.677 & 0.687 \\
\hline AIC*n: & 1022.168 & 1014.421 & 1013.843 \\
\hline BIC: & -50.166 & -42.216 & -33.89 \\
\hline
\end{tabular}

Note: Models are estimated using a probit link function with recycling (2008) as dependent variable; Standard errors of the individual coefficients in italics; $* * *$ indicates significance at $1 \%, * *$ at $5 \%$ and $*$ at $10 \%$ level. All models report p $<0.000$ for the LR test. 
Table 3: Determinants of recycling participation

\begin{tabular}{|c|c|c|c|}
\hline MODEL & $\begin{array}{l}\text { a.Basic } \mathbf{D f} / \mathbf{d x} \\
\text { S.E. }\end{array}$ & $\begin{array}{l}\text { b.Vote } \mathbf{D f} / \mathbf{d x} \\
\text { S.E. } \\
\end{array}$ & $\begin{array}{l}\text { c.Attach Df/dx } \\
\text { S.E. }\end{array}$ \\
\hline COLLECT-REC & $\begin{array}{l}\mathbf{0 . 0 5 5} * * \\
-0.023 \\
\end{array}$ & $\begin{array}{l}\mathbf{0 . 0 5 4} * * \\
-0.023 \\
\end{array}$ & $\begin{array}{l}\mathbf{0 . 0 5 3} * * \\
-0.023 \\
\end{array}$ \\
\hline COLLECT-MXD & $\begin{array}{l}\mathbf{0 . 0 1 9} \\
-0.013 \\
\end{array}$ & $\begin{array}{l}\mathbf{0 . 0 1 9} \\
-0.013 \\
\end{array}$ & $\begin{array}{l}\mathbf{0 . 0 1 8} \\
-0.013 \\
\end{array}$ \\
\hline FREE-BAGS & $\begin{array}{l}\mathbf{0 . 1 2 4} * * * \\
-0.026 \\
\end{array}$ & $\begin{array}{l}\mathbf{0 . 1 2 2} * * * \\
-0.026 \\
\end{array}$ & $\begin{array}{l}\mathbf{0 . 1 2 3} * * * \\
-0.026\end{array}$ \\
\hline INFO-TYPES & $\begin{array}{l}\mathbf{- 0 . 0 1 5} \\
-0.016 \\
\end{array}$ & $\begin{array}{l}\mathbf{- 0 . 0 1 6} \\
-0.016 \\
\end{array}$ & $\begin{array}{l}\mathbf{- 0 . 0 1 3} \\
-0.016\end{array}$ \\
\hline USES-SITE & $\begin{array}{l}\mathbf{- 0 . 0 2 5} * * * \\
-0.009 \\
\end{array}$ & $\begin{array}{l}\mathbf{- 0 . 0 2 4} * * * \\
-0.009 \\
\end{array}$ & $\begin{array}{l}\mathbf{- 0 . 0 2 8} * * * * \\
-0.009 \\
\end{array}$ \\
\hline SPACE & $\begin{array}{l}\mathbf{0 . 1 0 5 * * * *} \\
-0.026 \\
\end{array}$ & $\begin{array}{l}\mathbf{0 . 1 0 3} * * * * \\
-0.026 \\
\end{array}$ & $\begin{array}{l}\mathbf{0 . 1 1 4} * * * * \\
-0.026\end{array}$ \\
\hline SINGLE & $\begin{array}{l}\mathbf{- 0 . 1 0 1 * * *} \\
-0.038\end{array}$ & $\begin{array}{l}\mathbf{- 0 . 1 0 4} * * * \\
-0.038\end{array}$ & $\begin{array}{l}-\mathbf{- 0 . 0 9 9} * * * * \\
-0.038\end{array}$ \\
\hline WASTE & $\begin{array}{l}\mathbf{0 . 0 0 5} * * * \\
-0.001 \\
\end{array}$ & $\begin{array}{l}\mathbf{0 . 0 0 5} * * * \\
-0.001\end{array}$ & $\begin{array}{l}\mathbf{0 . 0 0 5} * * * \\
-0.001\end{array}$ \\
\hline EFFICACY & $\begin{array}{l}\mathbf{0 . 0 1 9} * * * \\
-0.006\end{array}$ & $\begin{array}{l}\mathbf{0 . 0 1 9} * * * \\
-0.006\end{array}$ & $\begin{array}{l}\mathbf{0 . 0 2 0} * * * \\
-0.006\end{array}$ \\
\hline PRO-ENV & $\begin{array}{l}\mathbf{0 . 0 2 4} * * * \\
-0.004 \\
\end{array}$ & $\begin{array}{l}\mathbf{0 . 0 2 4} * * * \\
-0.004 \\
\end{array}$ & $\begin{array}{l}\mathbf{0 . 0 2 4} * * * * \\
-0.004 \\
\end{array}$ \\
\hline FEMALE & $\begin{array}{l}\mathbf{0 . 0 4} \\
-0.032\end{array}$ & $\begin{array}{l}\mathbf{0 . 0 4 5} \\
-0.032\end{array}$ & $\begin{array}{l}\mathbf{0 . 0 4 6} \\
-0.032\end{array}$ \\
\hline AGE & $\begin{array}{l}\mathbf{0 . 0 0 0} \\
-0.001 \\
\end{array}$ & $\begin{array}{l}\mathbf{0 . 0 0 0} \\
-0.001-- \\
\end{array}$ & $\begin{array}{l}\mathbf{- 0 . 0 0 1} \\
-0.001 \\
\end{array}$ \\
\hline EDUC & $\begin{array}{l}\mathbf{0 . 0 4 4} * * * \\
-0.016\end{array}$ & $\begin{array}{l}\mathbf{0 . 0 4 7} * * * \\
-0.016\end{array}$ & $\begin{array}{l}\mathbf{0 . 0 4 3} * * * \\
-0.016\end{array}$ \\
\hline VOTEPN & & $\begin{array}{l}\mathbf{- 0 . 0 2} \\
-0.038 \\
\end{array}$ & \\
\hline VOTEPL & & $\begin{array}{l}\mathbf{0 . 0 1 7} \\
-0.03 \\
\end{array}$ & \\
\hline INTEREST & & & $\begin{array}{l}\mathbf{0 . 0 3 5} \text { *** } \\
-0.015\end{array}$ \\
\hline IDEOLOGY & & & $\begin{array}{l}\mathbf{0 . 0 0 1} \\
-0.01 \\
\end{array}$ \\
\hline ATTACH-PN & & & $\begin{array}{l}\mathbf{- 0 . 0 4 9} \\
-0.038 \\
\end{array}$ \\
\hline ATTACH-PL & & & $\begin{array}{l}\mathbf{- 0 . 0 1} \\
-0.032 \\
\end{array}$ \\
\hline $\mathbf{N}$ & 840 & 836 & 838 \\
\hline Log-Lik Intercept Only: & -432.517 & -430.25 & -432.043 \\
\hline Log-Lik Full Model: & -353.563 & -351.444 & -349.244 \\
\hline McFadden's Adj R2: & 0.143 & 0.137 & 0.141 \\
\hline Count R2: & 0.814 & 0.818 & 0.81 \\
\hline AIC*n: & 741.127 & 742.887 & 742.487 \\
\hline BIC: & -70.373 & -56.683 & -51.17 \\
\hline
\end{tabular}


Table 4: Determinants of recycling intent

\begin{tabular}{|c|c|c|c|c|}
\hline MODEL & $\begin{array}{c}\text { a.Basic Df/dx } \\
\text { S.E. } \\
\end{array}$ & $\begin{array}{c}\text { b.Vote } \mathbf{D f} / \mathbf{d x} \\
\text { S.E. } \\
\end{array}$ & $\begin{array}{c}\text { c.Attach Df/dx } \\
\text { S.E. }\end{array}$ & $\begin{array}{c}\text { d.Prime } \mathbf{D f} / \mathbf{d x} \\
\text { S.E. }\end{array}$ \\
\hline \multirow[t]{2}{*}{ FREE-BAGS } & $0.043 * * *$ & $0.455 * * *$ & $0.042 * * *$ & $0.059 * * *$ \\
\hline & -0.014 & -0.17 & -0.015 & -0.016 \\
\hline \multirow[t]{2}{*}{ FEMALE } & 0.018 & 0.182 & 0.02 & \\
\hline & -0.018 & -0.166 & -0.019 & \\
\hline \multirow[t]{2}{*}{ AGE } & 0 & -0.004 & $\mathbf{0}$ & \\
\hline & -0.001 & -0.006 & -0.001 & \\
\hline \multirow[t]{2}{*}{ EDUC } & $0.019 * *$ & $0.196 * *$ & $0.020 * *$ & $0.024 * * *$ \\
\hline & -0.009 & -0.09 & -0.009 & -0.008 \\
\hline \multirow[t]{2}{*}{ YEARS KERB } & $0.017 * * *$ & $0.166 * * *$ & $0.017 * * *$ & $0.021 * * *$ \\
\hline & -0.003 & -0.03 & -0.003 & -0.003 \\
\hline \multirow[t]{2}{*}{ INTEREST } & & & -0.006 & -0.006 \\
\hline & & & -0.009 & -0.009 \\
\hline \multirow[t]{2}{*}{ IDEOLOGY } & & & -0.009 & $-0.010 *$ \\
\hline & & & -0.006 & -0.006 \\
\hline \multirow[t]{2}{*}{ ATTACH-PN } & & & 0.004 & 0.041 \\
\hline & & & -0.021 & -0.031 \\
\hline \multirow[t]{2}{*}{ ATTACH-PL } & & & 0.002 & 0.003 \\
\hline & & & -0.018 & -0.026 \\
\hline \multirow[t]{2}{*}{ PRIME } & & & & 0 \\
\hline & & & & -0.021 \\
\hline \multirow[t]{2}{*}{ PRIME*PN } & & & & $-0.079 *$ \\
\hline & & & & -0.042 \\
\hline \multirow[t]{2}{*}{ PRIME*PL } & & & & -0.007 \\
\hline & & & & -0.035 \\
\hline \multirow[t]{2}{*}{ VOTEPN } & & -0.166 & & \\
\hline & & -0.204 & & \\
\hline \multirow[t]{2}{*}{ VOTEPL } & & 0.013 & & \\
\hline & & -0.171 & & \\
\hline $\mathrm{N}$ & 912 & 905 & 902 & 905 \\
\hline R-squared & & & & 0.081 \\
\hline Log-Lik Intercept Only & -205 & -204.6 & -204.39 & \\
\hline Log-Lik Full Model: & -173.146 & -172.45 & -171.382 & \\
\hline McFadden's R2: & 0.155 & 0.157 & 0.162 & \\
\hline McFadden's Adj R2: & 0.116 & 0.098 & 0.093 & \\
\hline Max-Likelihood R2: & 0.067 & 0.068 & 0.071 & \\
\hline Count R2: & 0.941 & 0.94 & 0.94 & \\
\hline AIC*n: & 362.292 & 368.91 & 370.76 & \\
\hline BIC': & -29.646 & -16.59 & 4.78 & \\
\hline
\end{tabular}

Note: Models $a, b, c$ are estimated using a probit link function with recycling intent as the dependent variable; Model $d$ is fitted with STATA's regress command. Standard errors of the individual coefficients in italics; All models report $p<0.000$ for the LR test. 
